\title{
Uma análise da progressão dos alunos cotistas sob a primeira ação afirmativa brasileira no ensino superior: o caso da Universidade do Estado do Rio de Janeiro
}

Alvaro Alberto Ferreira Mendes Junior

\section{Resumo}

Este artigo examina a progressão de candidatos cotistas e não cotistas ingressantes em 2005 na instituição responsável pela primeira ação afirmativa no ensino superior brasileiro. Os resultados foram reveladores. Em relação aos coeficientes de rendimento (CR), foi possível perceber um pior desempenho entre os cotistas. Além disto, mostramos que a diferença entre os não cotistas e cotistas é maior em cursos com alta dificuldade relativa, e que os diferenciais de CR não tem diminuído significativamente ao longo do curso. Quando o foco da análise se direciona para as taxas de graduação e evasão, notamos um melhor desempenho entre os cotistas. A partir da análise da coorte definida, mostramos que os cotistas apresentam maiores taxas de graduação em 2009, 2010 e 2011. Também apresentam menores evasões durante o primeiro ano e ao restante do curso. Esta pesquisa conclui que os cotistas matriculados na UERJ tendem a atribuir um alto valor ao curso em que ingressam. Por isto, persistem em uma maior proporção na universidade a despeito de menores coeficientes de rendimento médios.

Palavras-chave: Ação Afirmativa. Cotas. Progressão. UERJ

\section{Introdução}

Existem várias pesquisas que evidenciam os benefícios privados e públicos da educação. Ioschpe (2004) mostra estudos internacionais que utilizam variações da equação de Mincer e taxas internas de retorno para comprovar o prêmio aos

\footnotetext{
Doutorando em Ciências Econômicas pela Universidade Federal de Minas Gerais (UFMG). E-mail: alvaromendes@ufmg.br. Agradecimentos ao DEAPI/UERJ pelas autorizações necessárias para a pesquisa e à consultora de Business Intelligence da UERJ, Érika Araújo, pelas contribuições e constante suporte em relação aos dados.
} 
salários que mais anos de estudo trazem a um indivíduo. Belfield (2003) cita outro conjunto de artigos que comprova o impacto positivo da educação no bemestar da população estadunidense, como: queda média de aprisionamentos, de cigarros consumidos e de pessoas viciadas em drogas ilícitas, além do aumento da participação política e dos gastos por filho.

Analisando os retornos para o Brasil, Neri (2008) conclui que os salários médios de quem possui o ensino superior são mais do que o dobro daqueles que têm o ensino médio como grau máximo. Suliano e Siqueira (2012) mostram que os retornos por um ano de estudo no Sudeste e no Nordeste estão em $13 \%$ e $16 \%$, respectivamente.

Assim, quando o governo investe em universidades públicas de alta qualidade, o faz por duas razões. Primeiro, porque espera que os egressos, com o conhecimento adquirido em sala de aula, obtenham uma maior produtividade no mercado de trabalho. Depois pelo motivo da educação ser reconhecidamente uma fonte geradora de externalidades positivas dentro de uma nação.

Para que esses objetivos de política educacional sejam atingidos plenamente é necessário que os recém-matriculados na universidade sejam capazes de progredir nos períodos até a graduação. Mesmo que evadam ao longo do curso, os alunos podem obter maiores retornos no mercado de trabalho em comparação com a situação de não terem ingressado no ensino superior. Porém, se estamos preocupados em maximizar os retornos educacionais, isto não é o bastante. Conseguir manter os alunos até a formatura torna-se então uma condição necessária para que a missão de uma instituição de ensino superior (IES) seja cumprida integralmente.

Através da análise dos desempenhos educacionais no ensino superior, muitos estudos internacionais procuram avaliar em que medida a universidade está conseguindo cumprir a sua missão. Eles costumam ser avaliados sob três óticas: as taxas de graduação, os coeficientes de rendimento médio (CRs) no ensino superior e os salários no mercado de trabalho.

Em relação às taxas de graduação, Levin et al (1984) e Robst, Keil e Russo (1998) mostram que elas dependem de muitos fatores externos ao controle das IES. Apontam o ambiente familiar, a influência da comunidade, a realização 
escolar anterior, habilidades mentais, atitudes e motivação do aluno como algumas variáveis que explicam o processo de graduação. Em relação a estas características, as IES possuem um espaço reduzido para atuação.

Existem, porém, variáveis que estão sob o controle das IES e que, por isso, são passíveis de administração. Bowen eBok (1998) e Carnevale e Rose (2003) mostram que, quanto maior a qualidade da universidade, maior a probabilidade de graduação. Isso se daria pelo fato de estas instituições possuírem uma melhor infraestrutura para tratar casos problemáticos e por terem uma composição de alunos conscientes do valor agregado daquele ensino aos seus retornos salariais. Muriel e Giroletti (2010) citam exemplos de organização interna que podem impactar positivamente as taxas de graduação como uma ouvidoria eficiente além de apoio psicopedagógico e financeiro para alunos em dificuldades.

Para explicar as taxas de graduação no ensino superior, três variáveis que representam o desempenho anterior do aluno têm-se mostrado particularmente importantes. O CR médio obtido no ensino médio, a posição do aluno universitário na sua escola de ensino médio e o resultado obtido no scholastic aptitude test $\left(\mathrm{SAT}^{1}\right)$. Scott, Bailey e Kienzl (2006) mostram que uma maior pontuação no SAT leva a uma maior probabilidade de graduação no ensino superior. Outros estudos também expõem a importância do desempenho acadêmico anterior para a conclusão com êxito de um aluno no nível universitário. (BAI; CHI, 2011; COHN et al, 2004; O’REAR; SUTTON; RUBIN, 2010).

As características que mais afetam as taxas de graduação parecem ser as mesmas que impactam o desempenho em termos de CRs médios do ensino superior. Griffith (2008) evidencia que as três variáveis relacionadas acima também são importantes preditoras do grade point average $\left(\mathrm{GPA}^{2}\right)$ no ensino superior. Robst, Keil e Russo (1998) concluem que o próprio GPA é correlacionado com as taxas de graduação e afirmam que o aumento em um ponto do primeiro indicador impacta as taxas de graduação em $9 \%$.

Para o caso brasileiro, Waltenberg e Carvalho (2012) mostram que os ingressantes através de ações afirmativas em IES públicas estaduais apresentam

1 O SAT é um exame padronizado conduzido nos EUA para alunos do ensino médio que serve como parâmetro para admissão pelas universidades. As notas no exame variam de 600 a 2400 . Embora não seja o único critério relevante de entrada nos processos seletivos estadunidenses, quanto a abrangência e relevância, pode ser comparado ao Exame Nacional do Ensino Médio (ENEM).

2 O GPA é um sistema de pontuação muito utilizado nos EUA. Ao contrário dos coeficientes de rendimento (CR) utilizados no Brasil que variam de 0 a 10, a escala do GPA inicia-se em 0 e apresenta um valor máximo de 4. 
um resultado em termos de CR médio $8,8 \%$ inferior quando comparados aos não beneficiários. Esta pesquisa possui abrangência nacional e utilizou os dados do Exame Nacional de Desempenho de Estudantes (ENADE). O desempenho inferior apresentado pelos cotistas durante a faculdade é um resultado esperado para as universidades estaduais, à medida em que ingressantes por ações afirmativas se classificam, na média, com notas relativamente baixas no vestibular.

Restringir a análise às duas primeiras dimensões pode não ser suficiente para uma melhor avaliação dos benefícios da educação. Olbrecht (2009) revela que os atletas bolsistas analisados em uma universidade americana apresentaram menores coeficientes de rendimento do que o restante da faculdade. Mesmo assim, obtiveram um salário médio 10,7\% maior em empregos convencionais do que os alunos regulares. Esta aparente contradição possui uma justificativa teórica razoável. $\mathrm{O}$ autor argumenta que os atletas possuem uma maior autodisciplina e capacidade de trabalhar em equipe. Tais fatores exerceriam uma influência positiva na produtividade e, por consequência, nos salários dos egressos que foram atletas bolsistas durante o tempo de faculdade.

O objetivo deste artigo é avaliar como o desempenho de cotistas e não cotistas se manifesta em uma universidade que utilize ações afirmativas no Brasil. Para permitir esta análise utilizaremos estatísticas descritivas para identificar como estão os dois grupos em termos de taxas de graduação e coeficientes de rendimento médio. Como não é possível rastrear os alunos formados até o mercado de trabalho, este artigo não pretende avaliar os retornos salariais dos egressos da UERJ.

A estrutura do artigo segue o seguinte formato: a próxima seção apresenta uma revisão bibliográfica sobre desempenho educacional e ações afirmativas. A seção seguinte expõe a metodologia utilizada na pesquisa. Depois, são detalhados os resultados encontrados para a UERJ em termos de coeficientes de rendimento médio e de indicadores de progressão (graduação e evasão). Por fim, são apresentadas as principais conclusões deste artigo.

\section{0 desempenho educacional e as ações afirmativas}

As ações afirmativas alteram os resultados educacionais de uma universidade. Assim, precisamos considerar esse fato ao analisarmos os indicadores de 
progressão e os CRs médios. Ao criar um grupo relevante de alunos com características socioeconômicas diferentes dos outros ingressantes, a política de cotas da UERJ afeta a progressão de duas formas principais.

Primeiro, pelo fato de a nota média de entrada dos alunos cotistas no vestibular ser inferior à dos alunos não cotistas diminuindo assim a eficiência das IES. Mostramos na introdução que o desempenho anterior costuma ser uma explicativa relevante dos resultados no ensino superior, nos Estados Unidos. Assim, esperamos encontrar um desempenho menor entre candidatos cotistas. Este risco é percebido na argumentação de Pedrosa et al (2007) que explicita a possibilidade de que as ações afirmativas possam terminar por diminuir os resultados acadêmicos do corpo estudantil das IES. Em uma pesquisa sobre ações afirmativas e considerando a realidade da UERJ, Mendes Junior e Mello e Souza (2012) mostram que os candidatos cotistas apresentam notas no vestibular menores do que a contraparte não cotista. Logo, este diferencial de resultado na entrada poderia afetar o desempenho dos cotistas na progressão dentro da universidade.

Segundo, porque os alunos cotistas são em sua maioria advindos de famílias com baixas condições socioeconômicas e tal característica pode favorecer uma maior probabilidade de abandono dos estudos no nível de ensino superior. Esta correlação se justifica pelo fato de que pessoas com menor renda se veem mais pressionadas a trabalhar e por também possuir um menor acesso a recursos escolares como cópias de textos, livros e passagens.

Existem alguns estudos que abordam a relação entre ações afirmativas e a retenção dos alunos até a conclusão do curso. Sander (2004) argumenta que a eliminação de preferências baseadas em raça pode levar a um aumento na produção de advogados negros. $\mathrm{O}$ autor mostra que a ação afirmativa leva muitos negros a se classificarem para universidades onde de outro modo não conseguiriam a admissão. Como o nível de exigência dessas faculdades tende a ser maior, a evasão entre os cotistas acaba sendo particularmente alta. Com a eliminação da ação afirmativa os negros acabariam por entrar em faculdades menos seletivas, onde teriam uma maior chance de graduação. Assim, o hiato das notas entre não cotistas e cotistas, quando relevante, pode, ao invés de ajudar, prejudicar a população que busca beneficiar. Isto é conhecido como "mismatch hypothesis". Crosby e VanDeVeer (2000) argumentam que, em universidades de elite, minorias medíocres podem sofrer de ansiedade e dúvida extra que não 
sentiriam em universidades menos seletivas. Sowell (2004) concorda com esta argumentação e mostra que na Universidade da Califórnia, em Berkeley, onde as diferenças entre as médias do SAT de não beneficiados e beneficiados pelas ações afirmativas ultrapassaram trezentos pontos em 1988, 70\% dos negros não concluíram a faculdade.

Porém outros estudos têm mostrado que todos os grupos aumentam a probabilidade de graduação quando frequentam universidades seletivas, como, por exemplo, Bowen e Bok (1998) e Carnevale e Rose (2003). Griffith (2008) mostra que mais cem pontos na média (do SAT) apresentada pelos alunos matriculados aumentam em $1,7 \%$ a probabilidade de graduação em seis anos. Logo, como os cotistas se graduam mais quando alocados em instituições de ponta, a mismatch hypothesis não seria válida. Além disto, os cotistas que se graduam em uma instituição seletiva apresentam um maior prêmio salarial no mercado de trabalho, em comparação com cotistas egressos de IES com um menor desempenho no SAT. Nos Estados Unidos, a seletividade é comumente definida a partir das médias no SAT apresentadas pelos alunos de cada instituição. Assim, Dale e Krueger (2002) mostram que estudantes com um perfil socioeconômico desfavorecido podem melhorar os seus ganhos em $8 \%$, caso optem por se matricular em uma faculdade mais seletiva.

Embora a instituição das cotas pareça realmente favorecer os grupos contemplados, isso não significa que inexista um problema de diferenciais de desempenho entre aqueles não beneficiados e os beneficiados. Bowen e Bok (1998), mostram que os não contemplados por ações afirmativas possuem maiores CRs médios tanto em universidades renomadas como em instituições medianas. Griffith (2008) mostra, porém, que o hiato no CR dos cotistas e não cotistas pode diminuir ao longo do curso. Knapp, Kelly-Reid e Ginder (2010) revelam que as taxas de graduação no ensino superior em seis anos, para as principais raças estadunidenses, apresentam a seguinte proporção: afro-americanos (39\%), hispânicos (49\%) e brancos (59\%). Bai e Chi (2011) chegam à conclusão de que as minorias étnicas também obtiveram CRs médios inferiores no ensino superior chinês.

Esses estudos parecem indicar, em sua maioria, que tais políticas têm sido benéficas para os candidatos-alvo das ações afirmativas. Porém, também revelam que há um custo para a sociedade em termos de um hiato no desempenho entre os grupos não cotistas e cotistas. Diferenças são percebidas tanto ao nível dos CRs médios quanto ao nível das taxas de graduação. 
As seções abaixo detalham os resultados encontrados na UERJ, que revelam tanto conclusões que vão ao encontro dessas experiências internacionais (maiores CRs médios entre o grupo não cotista), como particularidades não verificadas em artigos anteriores (maiores taxas de graduação entre os cotistas).

\section{O Sistema de Cotas na UERJ}

A UERJ é a primeira instituição de ensino superior no Brasil a adotar ações afirmativas. No período de 2003 até 2012, ingressaram pelo sistema de cotas 16607 pessoas das quais 4738 (28,53\%) já se formaram e 4985 (30,01\%) evadiram. Os demais alunos cotistas se encontram matriculados vivendo o desafio de terminar a faculdade mesmo sofrendo com um ambiente familiar desfavorável. Desta forma, entender como os grupos cotistas e não cotistas passam pelos diversos períodos, rumo à evasão ou à graduação é de grande interesse para os gestores de políticas educacionais. Isso porque um bom desempenho relativo pelos cotistas pode servir como um forte argumento para a manutenção da política de cotas e um resultado contrário, como uma justificativa para a sua reforma ou eliminação.

O sistema de cotas da UERJ é regulamentado por lei estadual e teve inicio no vestibular para o acesso à universidade em 2003. Após revogações e alterações nos projetos originais, a lei vigente que estabelece as diretrizes desta política, é a de $\mathrm{N}^{\circ} 5346 / 2008$. Ela estabelece os seguintes percentuais de reservas de vagas: $20 \%$ para estudantes negros e indígenas; $20 \%$ para os estudantes oriundos da rede pública de ensino; $5 \%$ para pessoas com deficiências e filhos de policiais civis, militares, inspetores de segurança ou administração penitenciária mortos ou incapacitados por razão de serviço. Caso opte por concorrer à reserva de vagas para negros e indígenas, o candidato deve encaminhar uma autodeclaração onde se identifica como negro (ou indígena). Como a instituição não estipula controles em relação à autodeclaração, é possível que candidatos que se percebem como brancos possam aplicar este tipo de cota.

Mendes Junior e Mello e Souza (2012) avaliam o acesso na UERJ e mostram que a atual reserva de vagas é alta frente à demanda pelos cotistas. Este cenário faz com que os cotistas enfrentem uma baixa relação candidato vaga, se classificando para a UERJ com baixas notas no vestibular. Os pesquisadores mostram que, para muitas carreiras, todos os candidatos cotistas se classificam. O movimento inverso acontece entre os não cotistas, que se deparam com altas relações candidato vaga e altas notas de corte no vestibular. Como consequência, a UERJ acaba por apresentar um corpo discente bastante diversificado. 
Um exemplo da diversidade que a atual política da UERJ traz para o corpo de estudantes pode ser verificado em Mendes Junior e Waltenberg (2013). Simulando como diversas políticas de cotas afetam o corpo de estudantes classificados, os pesquisadores mostram que na ausência do atual sistema, a proporção de candidatos vindos de condições socioeconômicas favoráveis aumentaria significativamente.

Ao avaliarmos a progressão desses alunos, entendemos que possamos trazer resultados originais neste artigo. A alta porcentagem de vagas reservadas na UERJ (45\%) também é interessante para que seja possível entender possíveis impactos da lei de cotas, sancionada em agosto de 2012. Como se sabe, a referida lei institui 50\% das vagas em universidades públicas federais para candidatos egressos do ensino médio público observando-se o total de pretos, pardos e indígenas em cada unidade da federação. Assim, como ambas as políticas resultam em porcentagens parecidas de reserva de vagas, é possível que a experiência da UERJ sirva para contribuir no entendimento dos impactos da plena implantação da lei nas instituições federais.

Em nossa pesquisa sobre a progressão na UERJ nos concentramos em avaliar tão somente os resultados educacionais e não como a organização interna da universidade pode influenciar este desempenho. Assim, não é objeto de estudo a avaliação dos processos que conduzem ao atual patamar de retenção e notas médias.

Desta forma, a expansão de iniciativas como o Proiniciar $^{3}$ pode melhorar os resultados dos alunos cotistas. Como consequência, novas avaliações da política de cotas têm condições de apresentar resultados diferentes do que apontamos aqui.

\section{Metodologia de Pesquisa}

Para verificar a progressão na UERJ, são analisadas as informações extraídas da ferramenta de business inteligence $e^{4}(\mathrm{BI})$ sobre os CRs dos candidatos cotistas e as taxas de conclusão e evasão. As bases de dados do vestibular e da progressão

3 O Proiniciar é uma política de permanência da UERJ para os estudantes oriundos de reserva de vagas. Além das atividades acadêmicas, estes alunos recebem a Bolsa Permanência, atualmente no valor de $R \$$ 300,00 (trezentos reais), durante todo o curso universitário. Além disto, recebem desconto no restaurante universitário e parte do material didático para a realização das suas atividades.

4 O Business Intelligence (BI) é uma ferramenta desenvolvida pelo departamento de informática da UERJ (DINFO). Sua função é fornecer aos gestores da instituição dados relevantes sobre o vestibular e a progressão dos alunos na universidade. A ferramenta extrai informações detalhadas das bases de dados da UERJ de vestibular e graduação, as transforma e depois consolida em estatística descritiva. É um processo definido como extract, transform e load (ETL) e o seu resultado final é uma interface amigável capaz de municiar gestores com dados relevantes para tomadas de decisão. Desta forma, o sistema possibilita a geração de indicadores através da definição pelo usuário dos filtros a serem aplicados. 
atualmente não são relacionadas. Devido ao fato de apenas a primeira base conter informações detalhadas sobre cada candidato, isto acaba por impossibilitar que sejam utilizados modelos econométricos.

A coorte empregada na avaliação da progressão na UERJ foi constituída pelos ingressantes no vestibular de 2005. Temos informações disponíveis para 43 carreiras. Cada uma delas possui particularidades que podem fazer com que um candidato cotista se saia melhor ou pior do que um não cotista. Robst, Keil e Russo (1998) mostram, por exemplo, que a probabilidade de negros e mulheres concluírem o curso aumenta quando estão matriculados em carreiras onde as proporções de estudantes ou professores com as suas características são maiores.

Em nossa pesquisa, consideramos que a "dificuldade relativa do curso" é a principal questão que pode afetar o desempenho dos estudantes cotistas. Devido em boa parte aos condicionantes socioeconômicos a que estão submetidos, os cotistas obtiveram resultados insatisfatórios no vestibular. Conforme estudos citados na introdução, o vestibular é um bom representante para capturar os efeitos do conhecimento anterior do aluno. Desta forma, esperamos que os cotistas apresentem um rendimento inferior. Também esperamos que, diante de cursos desafiadores, com uma alta carga de matérias exatas, como matemática e física, por exemplo, os rendimentos do grupo cotista sejam ainda menores. Tais carreiras exigem uma carga maior de conhecimento anterior que pode ser decisiva para a progressão dos cotistas.

Para lidar com esta questão optamos por criar uma variável que chamamos de "dificuldade relativa do curso". Ela foi elaborada a partir do CR médio dos alunos de cada carreira em 2009 (ingressantes na UERJ em 2005 e que estavam cursando a faculdade em 2009). Considerando essa classificação, separamos as carreiras em três grupos: Alta, média e baixa dificuldade relativa.

Nossa visão se fundamenta no seguinte processo: Ótimos alunos em carreiras "fáceis" devem apresentar um coeficiente de rendimento bom. Ótimos alunos em carreiras "difíceis" e alunos medianos em carreiras "fáceis" tendem a apresentar um CR razoável e alunos medianos em carreiras "difíceis" provavelmente obterão os piores resultados. Assim, acreditamos que o CR médio de cada carreira em 2009 seja uma boa forma de se captar as dificuldades que os alunos estão tendo em progredir. A tabela 1 mostra uma relação parcial de cursos por nível de dificuldade relativa. 
As carreiras de história e engenharia química são bons exemplos para a relação da qualidade dos alunos com a dificuldade do curso. Em 2005, ambos os cursos apresentaram relações candidato/vaga em torno de dez. Seguindo a metodologia de Mendes Junior e Mello e Souza (2012), estes cursos seriam definidos como carreiras de alto prestígio. Tais carreiras são caracterizadas por uma alta concorrência e este fenômeno tende a resultar em notas de corte elevadas. Assim, pelo bom desempenho anterior dos alunos, poderíamos imaginar que, em ambas as carreiras, o coeficiente de rendimento médio no ensino superior seja elevado. Isto não ocorre para o caso da engenharia química que se encontra entre aquelas carreiras definidas como de alta dificuldade relativa. Ou seja, é um dos cursos em que os alunos possuem na média, baixos coeficientes de rendimento.

Esse diferencial se dá principalmente pelas exigências do curso de engenharia, que são reconhecidamente maiores do que as de outras áreas. Esse é um fenômeno que parece comum em carreiras com um alto grau de concentração de disciplinas exatas, onde destacamos a estatística, a matemática e as ciências econômicas.

\section{Coeficientes de Rendimento médios entre alunos não cotistas e cotistas}

A análise do desempenho dos alunos não cotistas e cotistas foi iniciada através dos CRs acumulados médios dos ingressantes em 2005 e que continuaram cursando a faculdade em 2006 e em 2009. Como uma minoria consegue se formar antes de 2009, esses estão excluídos da amostra. Os que desistiram ou foram expulsos da faculdade, também não constam na amostra. As informações com uma visão por carreira se encontram expostas na Tabela 1.

Tabela 1 - Coeficiente de rendimento acumulado médio dos alunos ingressantes em 2005 e que se encontram cursando a faculdade nos períodos de 2006 e 2009

\begin{tabular}{|c|c|c|c|c|c|c|c|c|c|c|}
\hline \multirow[t]{2}{*}{ Ranking } & \multirow[t]{2}{*}{ Carreira* } & \multirow{2}{*}{$\begin{array}{l}\text { Dificul- } \\
\text { dade } \\
\text { Relativa }\end{array}$} & \multicolumn{2}{|c|}{$\begin{array}{l}\text { CR } \\
\text { acumulado } \\
\text { médio }\end{array}$} & \multicolumn{2}{|c|}{$\begin{array}{l}\text { CR } \\
\text { acumulado } \\
\text { médio (NC) }\end{array}$} & \multicolumn{2}{|c|}{$\begin{array}{c}\text { CR } \\
\text { acumulado } \\
\text { médio }(C)\end{array}$} & \multicolumn{2}{|c|}{$\begin{array}{c}\text { Diferencial de CR } \\
\text { acumulado médio } \\
\text { entre } \mathrm{NC} \text { e C }\end{array}$} \\
\hline & & & 2006 & 2009 & 2006 & 2009 & 2006 & 2009 & 2006 & 2009 \\
\hline 1 & $\begin{array}{l}\text { Ciência da } \\
\text { Computação }\end{array}$ & Alta & 4,48 & 4,25 & 4,81 & 4,56 & 4,14 & 3,92 & $16,17 \%$ & $16,36 \%$ \\
\hline 2 & Física & Alta & 5,20 & 5,22 & 5,25 & 5,09 & 5,05 & 5,50 & $3,96 \%$ & $-7,48 \%$ \\
\hline
\end{tabular}

(continua) 


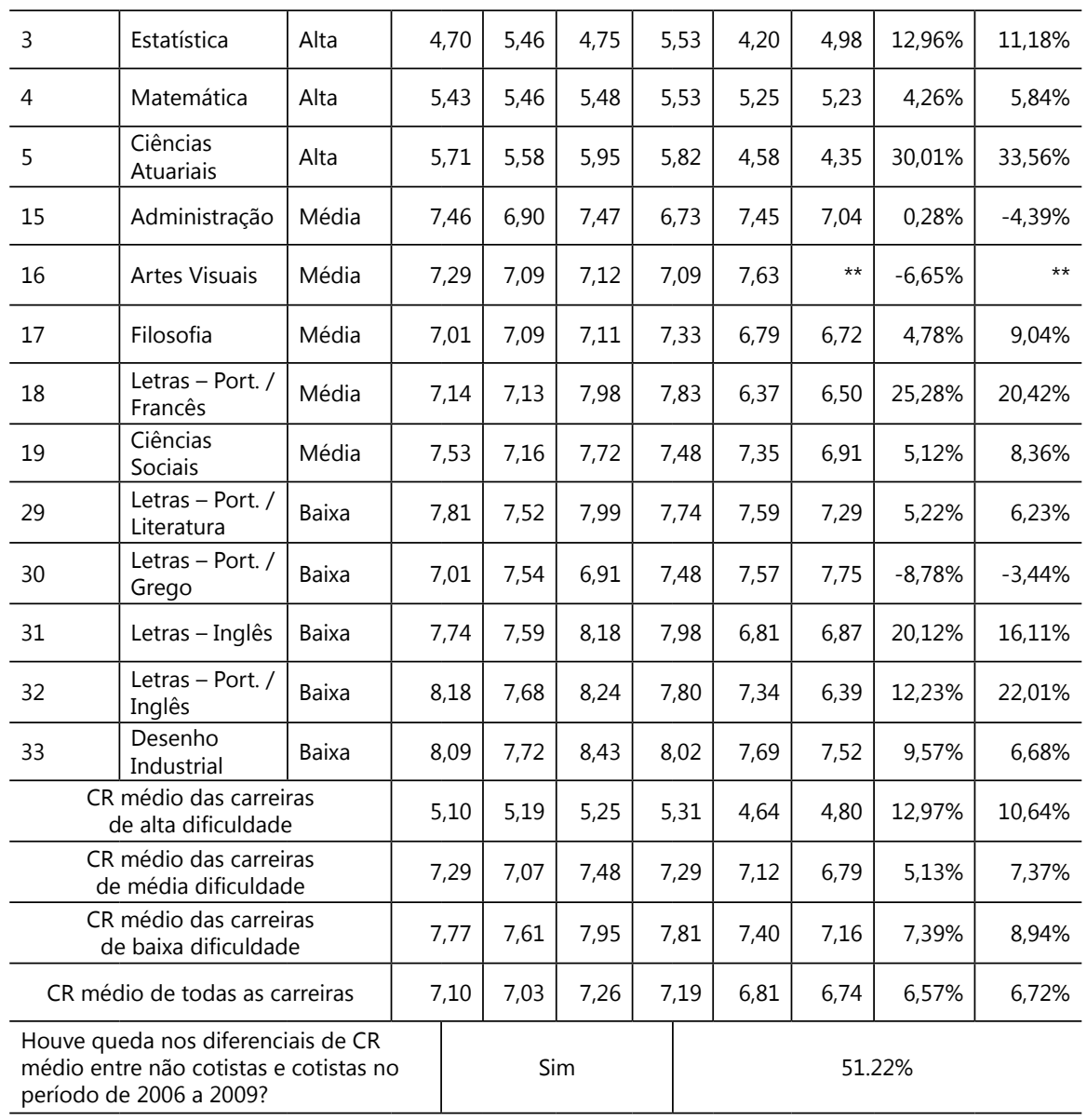

* A relação completa para todas as carreiras pode ser solicitada ao autor.

** Em 2009, todos os cotistas de artes visuais ingressantes em 2005 evadiram.

Fonte: O autor (2013).

Em relação aos diferenciais de CRs, entre os grupos de não cotistas e cotistas, nota-se que a diferença média das notas para todas as carreiras foi de 6,57\% em 2006 e 6,72\% em 2009 a favor dos não cotistas. A diferença em termos de notas médias aumenta conforme maior é a dificuldade relativa do curso. Em cursos difíceis, o diferencial chega a $12,97 \%$ e naqueles definidos como relativamente mais fáceis, o hiato diminui para 7,39\% no primeiro ano. Os diferenciais de rendimento podem alterar-se muito entre as carreiras. No ano de 2009, os não cotistas apresentaram um CR médio 33,33\% maior do que os cotistas para o curso de Ciências Atuariais ao mesmo tempo em que obtiveram um resultado inferior ao dos cotistas para o curso de Administração. 
Os dados da Tabela 2 fornecem outra visão sobre os resultados verificados anteriormente. Eles têm como objetivo mostrar quem apresentou o melhor CR médio em cada carreira, os cotistas ou os não cotistas. Nela podemos perceber que em $80,23 \%$ dos casos, o desempenho dos não cotistas foi melhor. Nos cursos mais difíceis, os não cotistas apresentam um rendimento melhor em $92,86 \%$ das carreiras, sendo que, em um terço delas, a diferença nos CRs se torna superior a 10\%.

Tabela 2 - Quem apresenta o maior CR médio acumulado (em \% das carreiras)?

\begin{tabular}{|c|c|c|c|c|}
\hline \multirow[t]{2}{*}{$\begin{array}{c}\text { Dificuldade } \\
\text { Relativa }\end{array}$} & \multirow[t]{2}{*}{ Grupo } & \multicolumn{2}{|c|}{$\begin{array}{l}\text { Quem apresenta o maior } \\
\text { CR médio acumulado } \\
\text { (em \% das carreiras) }\end{array}$} & \multirow{2}{*}{$\begin{array}{l}\text { Diferença maior } \\
\text { do que } 10 \% \text { em } \\
\text { ambos os períodos }\end{array}$} \\
\hline & & 2006 & 2009 & \\
\hline \multirow{2}{*}{ Alta } & Não Cotistas & $92.86 \%$ & $92.86 \%$ & $35.71 \%$ \\
\hline & Cotistas & $7.14 \%$ & $7.14 \%$ & $0.00 \%$ \\
\hline \multirow{3}{*}{ Média } & Não Cotistas & $85.71 \%$ & $57.14 \%$ & $14.28 \%$ \\
\hline & Cotistas & $14.29 \%$ & $28.57 \%$ & $0.00 \%$ \\
\hline & Sem informação & $0.00 \%$ & $14.29 \%$ & $0.00 \%$ \\
\hline \multirow{2}{*}{ Baixa } & Não Cotistas & $73.33 \%$ & $80.00 \%$ & $0.00 \%$ \\
\hline & Cotistas & $26.67 \%$ & $20.00 \%$ & $0.00 \%$ \\
\hline \multirow{3}{*}{ Total } & Não Cotistas & $83.72 \%$ & $76.74 \%$ & $23.25 \%$ \\
\hline & Cotistas & $16.28 \%$ & $18.6 \%$ & $0.00 \%$ \\
\hline & Sem informação & $0.00 \%$ & $4.65 \%$ & $0.00 \%$ \\
\hline \multirow{3}{*}{\multicolumn{2}{|c|}{$\begin{array}{c}\text { Quem apresenta o maior CR médio } \\
\text { acumulado (total das carreiras } \\
\text { analisadas) }\end{array}$}} & Não Cotistas & \multicolumn{2}{|r|}{$80.23 \%$} \\
\hline & & Cotistas & \multicolumn{2}{|r|}{$17.44 \%$} \\
\hline & & Sem informação & \multicolumn{2}{|r|}{$2.33 \%$} \\
\hline
\end{tabular}

Fonte: O autor (2013).

Esperávamos que, uma vez dentro da faculdade, os alunos cotistas conseguissem diminuir a diferença nos CRs entre o primeiro e o quarto ano. A evasão de muitos alunos não cotistas no primeiro ano e o efeito de pares dado pela convivência entre os dois grupos poderia gerar uma tendência de melhora nos resultados dos cotistas ao longo do curso. Não houve uma tendência definida, apesar de o diferencial entre os CRs de não cotistas e cotistas ter aumentado em 2009 (de 6,57\% para $6,72 \%$ ). Em uma visão por carreiras, os cotistas melhoraram marginalmente seu desempenho relativo. Ou seja, em 51,22\% das carreiras, a diferença das notas em 2009 foi menor do que em 2006. 
Assim, há um diferencial significativo em termos de notas médias para os grupos não cotistas e cotistas, o qual tende a ser expressivo em cursos que exigem uma maior dedicação e conhecimento anterior dos alunos. Porém, não é possível dizer que estes diferenciais de desempenho em termos de CR médio entre os não cotistas e cotistas diminuem ou aumentam ao longo do curso.

Com o intuito de entender melhor como se revela o hiato das notas entre os cotistas e os não cotistas, foi expandida a análise considerando apenas os estudantes concluintes. Ou seja, aqueles que ingressaram em 2005 e que se formaram na UERJ entre os anos de 2005 e 2012.

Os dados se encontram na Tabela 3. Através deles é possível verificar os diferenciais de desempenho para aqueles que tiveram sucesso em obter o diploma da graduação e que, por isso, estão em condições de exercer a sua profissão no mercado de trabalho.

Tabela 3 - Coeficiente de rendimento acumulado médio dos alunos ingressantes em 2005 e que concluíram a faculdade até o ano de 2012

\begin{tabular}{|c|c|c|c|c|c|}
\hline Ranking & Carreira* & $\begin{array}{l}\text { Dificulda- } \\
\text { de Relativa }\end{array}$ & $\begin{array}{l}\text { CR acumu- } \\
\text { lado médio } \\
\text { (Não } \\
\text { cotista) }\end{array}$ & $\begin{array}{c}\text { CR } \\
\text { acumulado } \\
\text { médio } \\
\text { (Cotista) }\end{array}$ & $\begin{array}{l}\text { Diferencial de } \\
\text { CR acumulado } \\
\text { médio entre } \\
\text { não cotistas e } \\
\text { cotistas }\end{array}$ \\
\hline 1 & Ciência da Computação & \multirow{5}{*}{ Alta } & 6,83 & 4,77 & $43,19 \%$ \\
\hline 2 & Física & & 8,04 & 4,64 & $73,17 \%$ \\
\hline 3 & Estatística & & 6,94 & 5,85 & $18,70 \%$ \\
\hline 4 & Matemática & & 7,07 & 7,06 & $0,15 \%$ \\
\hline 6 & Ciências Econômicas & & 7,51 & 6,77 & $10,98 \%$ \\
\hline 15 & Administração & \multirow{5}{*}{ Média } & 7,39 & 7,09 & $4,29 \%$ \\
\hline 17 & Filosofia & & 8,51 & 6,75 & $26,10 \%$ \\
\hline 18 & Letras - Port. / Francês & & 8,82 & 7,55 & $16,82 \%$ \\
\hline 19 & Ciências Sociais & & 7,96 & 7,31 & $8,90 \%$ \\
\hline 21 & $\begin{array}{l}\text { Letras - Port. / } \\
\text { Espanhol }\end{array}$ & & 7,95 & 7,42 & $7,16 \%$ \\
\hline
\end{tabular}

(continua) 


\begin{tabular}{|c|c|c|c|c|c|}
\hline 29 & $\begin{array}{l}\text { Letras - Port. / } \\
\text { Literatura }\end{array}$ & \multirow{5}{*}{ Baixa } & 8,22 & 8,02 & $2,47 \%$ \\
\hline 30 & Letras - Port. / Grego & & 7,90 & 7,74 & $2,07 \%$ \\
\hline 31 & Letras - Inglês & & 8,37 & 7,34 & $14,08 \%$ \\
\hline 32 & Letras - Port. / Inglês & & 8,04 & 7,60 & $5,74 \%$ \\
\hline 34 & Nutrição & & 8,21 & 7,71 & $6,46 \%$ \\
\hline \multicolumn{3}{|c|}{ CR médio das carreiras de alta dificuldade } & 7,40 & 6,36 & $16,35 \%$ \\
\hline \multicolumn{3}{|c|}{ CR médio das carreiras de média dificuldade } & 8,05 & 7,48 & $7,71 \%$ \\
\hline \multicolumn{3}{|c|}{ CR médio das carreiras de baixa dificuldade } & 8,42 & 8,05 & $4,69 \%$ \\
\hline \multicolumn{3}{|c|}{ CR médio de todas as carreiras } & 7,96 & 7,33 & $8,50 \%$ \\
\hline
\end{tabular}

* A relação completa para todas as carreiras pode ser solicitada ao autor. Fonte: O autor (2013).

Quando comparamos com o universo dos alunos que estavam matriculados em 2006, a diferença percebida em relação aos CRs médios dos alunos não cotistas e cotistas aumentou de 6,5\% para 8,5\% entre os concluintes até 2012 . Nos cursos de maior dificuldade, a diferença média ultrapassou os $16 \%$, caindo gradativamente para $7,71 \%$ e $4,69 \%$ quando consideradas as carreiras de média e baixa dificuldades relativas, respectivamente.

Da análise do comportamento detalhado por carreiras, foi possível perceber diferenças significantes em muitas delas. Podemos destacar o diferencial de 43,19\% para o curso apontado como o de maior dificuldade relativa, ciências da computação. Ou de 73,17\% para a física, onde os cotistas graduados apresentaram um CR médio de apenas 4,64 pontos contra 8,04 dos não cotistas. Outras diferenças substanciais de rendimento puderam ser percebidas para as carreiras de estatística, filosofia e letras (português-francês). Para todos estes casos, a diferença no CR médio acumulado final ultrapassou os $15 \%$.

Um maior diferencial de desempenho a favor dos não cotistas em termos de CR, quando considerado apenas o universo dos concluintes, mostra que talvez muitos cotistas estejam persistindo até a conclusão. A persistência dos cotistas, apesar do baixo rendimento relativo na faculdade, poderia acabar por diminuir a média deste grupo na comparação com os não cotistas. Essas impressões foram confirmadas na análise seguinte, que aborda a proporção de alunos não cotistas e cotistas que se graduam na UERJ. 


\section{Taxas de graduação e evasão entre alunos não cotistas e cotistas}

As próximas seções se concentram nas taxas de graduação e de evasão dos estudantes. Primeiro observa-se as taxas de conclusão dos alunos em três diferentes anos. As informações da Tabela 4 mostram a porcentagem dos ingressantes de 2005 que se formaram até 2009, até 2010 e até 2011. O foco da avaliação é o ano de saída da faculdade e os cortes foram escolhidos para que aproximássemos o indicador para uma visão que evidencia o universo de alunos que concluiu a faculdade em quatro, cinco ou seis anos.

Tabela 4 - Porcentagem de concluintes até 2009, 2010 e 2011 dos alunos ingressantes em 2005

\begin{tabular}{|c|c|c|c|c|}
\hline Ranking & Carreira e Tipo de Vaga* & Até 2009 & Até 2010 & Até 2011 \\
\hline \multirow{3}{*}{1} & Ciência da Computação & $0,00 \%$ & $0,00 \%$ & $5,66 \%$ \\
\hline & Cotista & $0,00 \%$ & $0,00 \%$ & $4,00 \%$ \\
\hline & Não Cotista & $0,00 \%$ & $0,00 \%$ & $7,14 \%$ \\
\hline \multirow{3}{*}{2} & Física & $1,75 \%$ & $2,34 \%$ & $4,09 \%$ \\
\hline & Cotista & $0,00 \%$ & $0,00 \%$ & $8,00 \%$ \\
\hline & Não Cotista & $2,05 \%$ & $2,74 \%$ & $3,42 \%$ \\
\hline \multirow{3}{*}{3} & Estatística & $10,58 \%$ & $15,38 \%$ & $23,08 \%$ \\
\hline & Cotista & $0,00 \%$ & $14,29 \%$ & $42,86 \%$ \\
\hline & Não Cotista & $11,34 \%$ & $15,46 \%$ & $21,65 \%$ \\
\hline \multirow{3}{*}{15} & Administração & $39,39 \%$ & $43,94 \%$ & $53,03 \%$ \\
\hline & Cotista & $42,59 \%$ & $50,00 \%$ & $64,81 \%$ \\
\hline & Não Cotista & $37,18 \%$ & $39,74 \%$ & $44,87 \%$ \\
\hline \multirow{3}{*}{16} & Artes Visuais & $0,00 \%$ & $25,00 \%$ & $25,00 \%$ \\
\hline & Cotista & $0,00 \%$ & $0,00 \%$ & $0,00 \%$ \\
\hline & Não Cotista & $0,00 \%$ & $33,33 \%$ & $33,33 \%$ \\
\hline \multirow{3}{*}{17} & Filosofia & $3,51 \%$ & $9,65 \%$ & $12,28 \%$ \\
\hline & Cotista & $0,00 \%$ & $4,00 \%$ & $12,00 \%$ \\
\hline & Não Cotista & $4,49 \%$ & $11,24 \%$ & $12,36 \%$ \\
\hline \multirow{3}{*}{29} & Letras - Port. / Literatura & $42,24 \%$ & $52,17 \%$ & $54,04 \%$ \\
\hline & Cotista & $50,82 \%$ & $59,02 \%$ & $62,30 \%$ \\
\hline & Não Cotista & $37,00 \%$ & $48,00 \%$ & $49,00 \%$ \\
\hline
\end{tabular}

(continua) 


\begin{tabular}{|c|c|c|c|c|}
\hline \multirow{3}{*}{30} & Letras - Port. / Grego & $30,00 \%$ & $40,00 \%$ & $40,00 \%$ \\
\hline & Cotista & $100,00 \%$ & $100,00 \%$ & $100,00 \%$ \\
\hline & Não Cotista & $22,22 \%$ & $33,33 \%$ & $33,33 \%$ \\
\hline \multirow{3}{*}{31} & Letras - Inglês & $26,03 \%$ & $42,47 \%$ & $46,58 \%$ \\
\hline & Cotista & $30,43 \%$ & $43,48 \%$ & $47,83 \%$ \\
\hline & Não Cotista & $24,00 \%$ & $42,00 \%$ & $46,00 \%$ \\
\hline \multirow{9}{*}{$\begin{array}{l}\text { Dificuldade } \\
\text { Relativa }\end{array}$} & \multicolumn{4}{|l|}{ Alta Dificuldade } \\
\hline & Cotistas & $12,45 \%$ & $19,54 \%$ & $28,74 \%$ \\
\hline & Não cotistas & $12,42 \%$ & $23,05 \%$ & $29,72 \%$ \\
\hline & \multicolumn{4}{|l|}{ Média Dificuldade } \\
\hline & Cotistas & $27,21 \%$ & $42,24 \%$ & $49,04 \%$ \\
\hline & Não cotistas & $23,49 \%$ & $38,38 \%$ & $42,07 \%$ \\
\hline & \multicolumn{4}{|l|}{ Baixa Dificuldade } \\
\hline & Cotistas & $40,57 \%$ & $55,49 \%$ & $61,40 \%$ \\
\hline & Não Cotistas & $35,74 \%$ & $50,66 \%$ & $53,83 \%$ \\
\hline \multirow{3}{*}{ Consolidado } & \multicolumn{4}{|l|}{ Total } \\
\hline & Cotistas & $27,07 \%$ & $39,47 \%$ & $46,74 \%$ \\
\hline & Não Cotistas & $24,16 \%$ & $37,67 \%$ & $42,15 \%$ \\
\hline
\end{tabular}

* A relação completa para todas as carreiras pode ser solicitada ao autor. Fonte: O autor (2013).

Os resultados são reveladores. Ao contrário do que é percebido em estudos internacionais, no caso da UERJ são os cotistas que possuem as maiores taxas de graduação. Quando esse grupo é comparado aos demais alunos, percebe-se que $46,74 \%$ dos cotistas se formaram contra $42,15 \%$ dos não cotistas.

O hiato a favor dos cotistas se mostra claro em duas dimensões: conforme avançam os anos e à medida que diminui a dificuldade relativa. Em relação à primeira questão, as taxas de graduação entre os cotistas crescem num ritmo maior com o passar dos anos. Em carreiras marcadas como de dificuldade média, houve um aumento de $27,21 \%$ para $49,04 \%$ entre 2009 e 2011 . Ou seja, 22 pontos percentuais. Entre aqueles não cotistas, o aumento foi de $23,49 \%$ para $42,07 \%$. Representando um acréscimo de 19 pontos percentuais. Em cursos de baixa dificuldade relativa, a diferença dos cotistas para os não cotistas aumentou de cerca de cinco pontos percentuais para oito. A exceção se deu em cursos de alta dificuldade relativa, onde no final de 2011 os não cotistas concluíram em maior proporção a faculdade. 
Em algumas carreiras esta diferença é mais expressiva. No curso de administração, por exemplo, $64,81 \%$ dos cotistas se formaram até 2011 enquanto este número para os não cotistas foi de $44,87 \%$. Em estatística $42,86 \%$ dos cotistas se graduaram contra $21,85 \%$ dos demais. Ou seja, para estes dois cursos, os cotistas obtiveram um resultado superior em cerca de 20 pontos percentuais.

Os dados da Tabela 5 mostram a progressão dos cotistas e não cotistas por outra visão. Ela expõe a quantidade de cursos onde os cotistas se graduaram em maior proporção, quando comparados com os não cotistas.

Tabela 5 - Porcentagem de cursos com maior graduação de cotistas em relação aos não cotistas, considerando os anos de 2009, 2010 e 2011 e o universo dos alunos ingressantes em 2005 (por dificuldade relativa do curso).

\begin{tabular}{c|r|r|r}
\hline $\begin{array}{c}\text { Porcentagem de cursos com maior } \\
\text { graduação de cotistas em relação aos } \\
\text { não cotistas }\end{array}$ & \multicolumn{2}{c}{ Até 2009} & Até 2010 \\
\hline Alta dificuldade relativa & $35,71 \%$ & $28,57 \%$ & $42,86 \%$ \\
\hline Média dificuldade relativa & $50,00 \%$ & $57,14 \%$ & $71,43 \%$ \\
\hline Baixa dificuldade relativa & $66,67 \%$ & $73,33 \%$ & $73,33 \%$ \\
\hline Total & $51,16 \%$ & $53,49 \%$ & $62,79 \%$ \\
\hline
\end{tabular}

Fonte: O autor (2013).

Desta forma percebe-se com clareza que os cotistas se saem cada vez melhor quando os anos avançam e quando estão cursando alguma das carreiras classificadas por nós como as mais fáceis. Conforme aumentam os anos, o percentual de cursos com maior graduação pelos beneficiários da ação afirmativa aumenta de 51,16\% das carreiras em 2009 para 62,79\% em 2011. Se considerarmos apenas as carreiras classificadas como de baixa dificuldade relativa, então a diferença a favor dos cotistas sai de $66,67 \%$ das carreiras em 2009 para $73,33 \%$ em 2011.

Da análise das taxas de graduação percebemos que, apesar de obterem um resultado pior do que aqueles não cotistas em termos de CR médio, os cotistas estão-se formando a taxas maiores do que o grupo não beneficiado. A nossa hipótese é de que embora estejam apresentando uma dificuldade elevada em progredir, a utilidade da faculdade para os grupos cotistas parece ser maior e tal valoração se tem traduzido em uma maior persistência e em taxas de graduação. 
A progressão entre os grupos não cotistas e cotistas também pode ser analisada pelas taxas de evasão. Optamos por dividir as taxas de evasão em duas tabelas: a Tabela 6 avalia os alunos que saíram da UERJ durante o primeiro ano, e a Tabela 7, que concentra os estudantes evadidos da faculdade no intervalo de um a quatro anos.

Tabela 6 - Taxa de evasão no primeiro ano dos ingressantes em 2005

\begin{tabular}{|c|c|c|c|c|c|c|}
\hline \multirow[b]{2}{*}{ Ranking } & \multirow[b]{2}{*}{ Carreiras* } & \multirow[b]{2}{*}{$\begin{array}{l}\text { Dificul- } \\
\text { dade } \\
\text { Relativa }\end{array}$} & \multicolumn{2}{|c|}{ Não cotistas } & \multicolumn{2}{|c|}{ Cotistas } \\
\hline & & & $\begin{array}{c}\text { \% de } \\
\text { Evasão }\end{array}$ & $\begin{array}{l}\text { \% de } \\
\text { Evasão por } \\
\text { grupo de } \\
\text { dificuldade } \\
\text { relativa }\end{array}$ & $\begin{array}{l}\% \text { de } \\
\text { Evasão }\end{array}$ & $\begin{array}{c}\text { \% de Eva- } \\
\text { são por } \\
\text { grupo de } \\
\text { dificulda- } \\
\text { de relativa }\end{array}$ \\
\hline 1 & $\begin{array}{l}\text { Ciência da } \\
\text { Computação }\end{array}$ & \multirow{5}{*}{ Alta } & $0,00 \%$ & \multirow{5}{*}{$18,00 \%$} & $0,00 \%$ & \multirow{5}{*}{$7,21 \%$} \\
\hline 2 & Física & & $31,01 \%$ & & $4,00 \%$ & \\
\hline 3 & Estatística & & $16,48 \%$ & & $0,00 \%$ & \\
\hline 4 & Matemática & & $20,93 \%$ & & $10,00 \%$ & \\
\hline 5 & Ciências Atuariais & & $17,17 \%$ & & $4,76 \%$ & \\
\hline 15 & Administração & \multirow{5}{*}{ Média } & $17,14 \%$ & \multirow{5}{*}{$15,40 \%$} & $5,56 \%$ & \multirow{5}{*}{$7,26 \%$} \\
\hline 16 & Artes Visuais & & $0,00 \%$ & & $0,00 \%$ & \\
\hline 17 & Filosofia & & $29,73 \%$ & & $4,00 \%$ & \\
\hline 18 & $\begin{array}{l}\text { Letras - Port. / } \\
\text { Francês }\end{array}$ & & $25,00 \%$ & & $5,56 \%$ & \\
\hline 19 & Ciências Sociais & & $27,45 \%$ & & $13,33 \%$ & \\
\hline 29 & $\begin{array}{l}\text { Letras - Port. / } \\
\text { Literatura }\end{array}$ & \multirow{5}{*}{ Baixa } & $23,71 \%$ & \multirow{5}{*}{$12,83 \%$} & $11,48 \%$ & \multirow{5}{*}{$3,87 \%$} \\
\hline 30 & Letras - Port. / Grego & & $44,44 \%$ & & $0,00 \%$ & \\
\hline 31 & Letras - Inglês & & $20,83 \%$ & & $13,04 \%$ & \\
\hline 32 & Letras - Port. / Inglês & & $9,59 \%$ & & $12,50 \%$ & \\
\hline 33 & Desenho Industrial & & $0,00 \%$ & & $0,00 \%$ & \\
\hline \multicolumn{3}{|c|}{ Consolidado por carreiras } & $15,62 \%$ & - & $5,84 \%$ & - \\
\hline
\end{tabular}

* A relação completa para todas as carreiras pode ser solicitada ao autor. Fonte: O autor (2013). 
A divisão nestas duas tabelas se inspira no artigo de Fletcher e Tienda (2008). Eles argumentam que o primeiro ano serve para que os estudantes se aclimatem às exigências do ensino superior. Os autores afirmam que, nos EUA, muitos dos alunos beneficiados pelas ações afirmativas nas IES costumam desistir já no inicio da faculdade pelo motivo de não conseguirem superar os desafios do ensino superior. Como apenas os melhores beneficiados tendem a permanecer, há uma queda nos diferenciais de desempenho entre os favorecidos e os não favorecidos pela ação afirmativa. Os autores mostraram que, mesmo controlando para uma série de variáveis, o diferencial de CR entre cotistas e não cotistas reduziu-se em $50 \%$ no intervalo de seis semestres.

Entendemos que o comportamento da evasão no primeiro ano pode ser diferente do verificado nos EUA. A explicação para que esse fenômeno possa apresentar um efeito contrário no Rio de Janeiro se justifica pelo fato de existirem inúmeras IES de alta qualidade no estado. Desta forma, esperamos que muitos dos alunos não cotistas que passam em mais de um vestibular acabem por optar por outras instituições, mesmo depois de terem efetuado a matrícula na UERJ. Há ainda aqueles que não atribuem um alto valor para a carreira em que iniciaram a faculdade e que, por isso, trancam suas matrículas para tentar um novo curso ou faculdade no ano posterior.

Essa subvaloração por não cotistas pode ser explicada em parte pela autoconfiança, pois sabem que são capazes de entrar em outra faculdade pública e em parte pelo ambiente familiar favorável, pois sabem que suas famílias podem arcar com os custos de uma faculdade privada de alta qualidade. Por estes fatores, ao contrário da realidade estadunidense exposta em Fletcher e Tienda (2008), supomos inicialmente que a evasão entre os não cotistas fosse particularmente expressiva no primeiro ano. Imaginamos ainda, que os diferenciais de desempenho em termos de CR médio diminuíssem quando comparamos ambos os grupos, pois uma parcela razoável dos melhores não cotistas acaba por abandonar a faculdade no primeiro ano.

Se em relação aos CRs não percebemos uma queda significativa nos diferenciais de desempenho entre períodos para a evasão, os dados confirmaram nossas expectativas. Entre os alunos não cotistas, 15,6\% abandonaram a UERJ no primeiro ano. Este número é percentualmente cerca de três vezes maior do que o apresentado pelos cotistas $(5,8 \%)$. Esta diferença sugere que a instituição deva preocupar-se também com a persistência dos não cotistas. Para os dois grupos, a evasão se revelou particularmente alta em cursos de alta dificuldade relativa com uma tendência de queda significativa em carreiras mais fáceis. Em todos os níveis de dificuldade a 
evasão entre os não cotistas foi maior. Na análise por carreiras a evasão deste grupo atinge o máximo em oceanografia, onde $69 \%$ dos alunos abandonaram a faculdade no primeiro ano. Quando analisamos o universo dos cotistas, a evasão máxima no primeiro ano foi de $26 \%$ em química. Mesmo em cursos de baixa dificuldade, a evasão entre os não cotistas permaneceu alta, em $12,8 \%$. Este valor é três vezes maior do que o apresentado pelos beneficiários da ação afirmativa, $3,8 \%$.

Após isto, avaliamos o comportamento da evasão entre o segundo e o quarto anos. O objetivo é captar como os alunos estão progredindo a partir do término dos desafios do primeiro ano dos seus cursos. Os resultados se encontram na Tabela 7. A diferença da evasão entre os dois grupos cai. Porém ela se mantém favorável aos cotistas, que continuam apresentando as menores taxas de evasão. Entre os não cotistas a evasão no período foi de $39,35 \%$ e para os cotistas, o resultado chegou a $32,88 \%$.

Tabela 7 - Taxa de evasão entre o segundo e quarto anos dos ingressantes em 2005

\begin{tabular}{|c|c|c|c|c|c|c|}
\hline \multirow[b]{2}{*}{ Ranking } & \multirow[b]{2}{*}{ Carreiras* } & \multirow[b]{2}{*}{$\begin{array}{l}\text { Dificul- } \\
\text { dade } \\
\text { Relativa }\end{array}$} & \multicolumn{2}{|c|}{ Não cotistas } & \multicolumn{2}{|c|}{ Cotistas } \\
\hline & & & $\begin{array}{l}\% \text { de } \\
\text { Evasão }\end{array}$ & $\begin{array}{l}\text { \% de Eva- } \\
\text { são por } \\
\text { grupo de } \\
\text { dificulda- } \\
\text { de relativa }\end{array}$ & $\begin{array}{l}\text { \% de } \\
\text { Evasão }\end{array}$ & $\begin{array}{l}\text { \% de Eva- } \\
\text { são por } \\
\text { grupo de } \\
\text { dificulda- } \\
\text { de relativa }\end{array}$ \\
\hline 1 & $\begin{array}{l}\text { Ciência da } \\
\text { Computação }\end{array}$ & \multirow{5}{*}{ Alta } & $7,14 \%$ & \multirow{5}{*}{$30,79 \%$} & $0,00 \%$ & \multirow{5}{*}{$26,45 \%$} \\
\hline 2 & Física & & $37,67 \%$ & & $24,00 \%$ & \\
\hline 3 & Estatística & & $36,08 \%$ & & $14,29 \%$ & \\
\hline 4 & Matemática & & $46,07 \%$ & & $50,00 \%$ & \\
\hline 5 & Ciências Atuariais & & $37,61 \%$ & & $38,10 \%$ & \\
\hline 15 & Administração & \multirow{5}{*}{ Média } & $57,69 \%$ & \multirow{5}{*}{$47,16 \%$} & $44,44 \%$ & \multirow{5}{*}{$39,83 \%$} \\
\hline 16 & Artes Visuais & & $0,00 \%$ & & $100,00 \%$ & \\
\hline 17 & Filosofia & & $38,20 \%$ & & $40,00 \%$ & \\
\hline 18 & $\begin{array}{l}\text { Letras - Port. / } \\
\text { Francês }\end{array}$ & & $45,83 \%$ & & $38,89 \%$ & \\
\hline 19 & Ciências Sociais & & $25,00 \%$ & & $11,11 \%$ & \\
\hline
\end{tabular}

(continua) 


\begin{tabular}{|c|c|c|c|c|c|c|}
\hline 29 & $\begin{array}{l}\text { Letras - Port. / } \\
\text { Literatura }\end{array}$ & \multirow{5}{*}{ Baixa } & $54,00 \%$ & \multirow{5}{*}{$44,97 \%$} & $49,18 \%$ & \multirow{5}{*}{$32,66 \%$} \\
\hline 30 & Letras - Port. / Grego & & $22,22 \%$ & & $7,14 \%$ & \\
\hline 31 & Letras - Inglês & & $50,00 \%$ & & $34,78 \%$ & \\
\hline 32 & Letras - Port. / Inglês & & $66,22 \%$ & & $62,50 \%$ & \\
\hline 33 & Desenho Industrial & & $15,00 \%$ & & $6,25 \%$ & \\
\hline \multicolumn{3}{|c|}{ Consolidado por carreiras } & $39,35 \%$ & - & $32,88 \%$ & - \\
\hline
\end{tabular}

* A relação completa para todas as carreiras pode ser solicitada ao autor. Fonte: O autor (2013).

A maior diferença percebida foi na dinâmica da evasão. No primeiro ano as evasões se concentraram em carreiras com alta dificuldade. Para os demais períodos, os abandonos são maiores em cursos de baixa dificuldade, independente do tipo de vaga (cotista ou não cotista). Podemos entender esta dinâmica como resultado de um processo onde as carreiras mais difíceis filtram os alunos com maior persistência e/ou habilidade já nos primeiros semestres, devido ao rigor das disciplinas que devem ser cursadas nos períodos iniciais. Os "sobreviventes" desta primeira etapa estariam preparados para progredir, com sucesso pelos demais períodos. Entre carreiras de menor dificuldade, os desafios iniciais são superáveis com uma maior facilidade e, por isso, a evasão neste tipo de curso parece mostrar um comportamento mais homogêneo entre os semestres.

\section{Conclusões}

Os resultados da análise empírica do acesso à UERJ, com foco na progressão dos alunos que se matricularam na UERJ durante o ano de 2005, foram reveladores. Indo ao encontro das pesquisas internacionais, identificamos que o desempenho dos não cotistas em termos de coeficiente de rendimento médio é superior. Entre os que possuíam matrícula ativa em 2009, a diferença a favor dos não cotistas se mostrou positiva em 6,72\%. Quando o universo dos alunos passou a ser a dos concluintes até o ano de 2012, a diferença aumentou para 8,50\%. Percebemos também que a magnitude dos diferenciais de desempenho em termos de CR médio entre os alunos subiu com o aumento da dificuldade relativa do curso, atingindo os $16,35 \%$ entre os concluintes das carreiras mais difíceis.

Como os candidatos não cotistas são os mais preparados, era de se esperar que, além de um resultado superior, em termos de notas médias, eles apresentassem 
maiores taxas de graduação. Dessa forma, um processo seletivo baseado unicamente na nota apresentada por cada candidato no vestibular seria aquele que geraria os maiores retornos educacionais independente da forma de avaliação. Isto pode não ser verdade para o caso da UERJ. Em nossa pesquisa, descobrimos que a persistência dos cotistas é maior e isto se traduz em maiores taxas de graduação. Logo, embora se tenham graduado com um coeficiente de rendimento médio menor do que os não cotistas foi o grupo cotista quem percentualmente mais se formou pela UERJ. Mostramos que as taxas de graduação entre os cotistas são maiores ao final de todos os anos analisados (2009, 2010 e 2011), atingindo em 2011 uma taxa de 46,74\% contra 42,15\% dos não beneficiários. Foi visto também que esta tendência se acentuou em cursos com baixa dificuldade relativa, chegando a sete pontos percentuais, em 2011.

Quando as evasões no primeiro ano e nos três anos posteriores foram analisadas, percebemos que o abandono pelos não cotistas foi particularmente alto no primeiro ano e se manteve superior à da contraparte cotista na abordagem consolidada dos períodos seguintes. A evasão dentro dos grupos foi grande em cursos de alta dificuldade no primeiro ano e, nos cursos de baixa e média dificuldade, após os dois primeiros períodos. Isto sugere que os cursos mais difíceis têm filtrado os melhores alunos já no começo da jornada dos potenciais formandos, o que não tem acontecido nas demais carreiras.

Da análise dos indicadores abordados, percebemos que apesar de obterem um resultado inferior em termos de notas médias, os cotistas estão-se formando a taxas maiores do que o grupo não beneficiado. Entendemos que, embora estejam apresentando uma dificuldade elevada em progredir, a utilidade da faculdade para os grupos cotistas parece ser maior e tal valoração se tem traduzido em uma maior persistência e taxas de graduação. Se por um lado, há uma perda de eficiência da universidade pelas graduações cotistas traduzidas em um CR menor e consequente menor habilidade esperada, por outro lado há um ganho vindo de maiores taxas de graduação que se traduzem em um menor desperdício de recursos.

Os críticos das ações afirmativas argumentam que tal política invariavelmente traz perdas significantes de eficiência para a universidade e para o país. Ao contrário do que poderíamos esperar, a política de cotas trouxe para a sociedade dois comportamentos contrários. Um positivo, através de maiores taxas de graduação e um negativo, resultado de coeficientes de rendimento menores. 
Por fim, entendemos que esta área do conhecimento demanda novas pesquisas aplicadas em outras universidades relevantes no Brasil. Assim, será possível subsidiar os formuladores de políticas educacionais com dados que mostrem os benefícios e custos que a instituição de uma ação afirmativa pode trazer.

\section{Referências}

BAI, C.; CHI, W. Determinants of undergraduate GPAs in China: college entrance examination scores, high school achievement, and admission route. MPRA, [S.l.], v. 5, n. 1, p.1-27, jan./fev. 2011.

BELFIELD, C. R. Economic Principles for Education: theory and evidence. Northampton: Edward Elgar Pub, 2003.

BOWEN, W.; BOK, D. The shape of the river: long-term consequences of considering race in college and university admissions. Princeton: Princeton University Press, 1998.

CARNEVALE, A.; ROSE, S. Socioeconomic status, race: ethnicity, and selective college admissions. New York: Century Foundation, 2003. 81 p.

$\mathrm{COHN}$ et al. Determinants of undergraduate GPAs: SAT scores, high-school GPA and high-school rank. Economics Of Education Review, [S.1.], n. 24, p. 577-586, 2004.

CROSBY, F.; VANDEVEER, C. Sex, race and merit: debating affirmative action in education and employment. Michigan: University Of Michigan Press, 2000. $352 \mathrm{p}$.

DALE, S. B.; KRUEGER, A. B. Estimating the payoff to attending a more selective college: an application of selection on observables and unobservables. The Quarterly Journal of Economics, [S.1.], v. 2, n. 106, p.1491-1527, 2002.

FLETCHER, J. M.; TIENDA, M. Race and Ethnic Differences in College achievement: does High School attended matter? SSRN Working Papers, [S.1.], v. 4, n. 66, p.1-36, 2008. 
GRIFFITH, A. Determinants of grades, persistence and major choice for lowincome and minority students. ILR Collection, [S.1.], v. 16, n. 41, p.1-42, jan./ abr. 2008.

IOSCHPE, G. (Org.). A ignorância custa um mundo: o valor da Educação no desenvolvimento do Brasil. São Paulo: Francis, 2004. 324 p.

KNAPP, L.; KELLY-REID, J.; GINDER, S. Enrollment in postsecondary institutions, Fall 2008: graduation rates, $2002 \& 2005$ cohorts: and financial statistics, fiscal year 2008. Washington: U.S. Department Of Education, 2010.

LEVIN et al. Educação e desigualdades no Brasil. Petrópolis: Vozes, 1984. 292 p.

MENDES JUNIOR, A. A. F.; MELLO E SOUZA, A. de. Uma análise dos determinantes do acesso à universidade sob uma ação afirmativa: o caso da UERJ. In: ENCONTRO NACIONAL DE ECONOMIA, 40., 2012, Pernambuco. Trabalhos apresentados...Pernambuco: ANPEC, 2012. P. 1-20.

MENDES JUNIOR, A. A. F.; WALTENBERG, F. D. Políticas de cotas não raciais aumentam a admissão de pretos e pardos na universidade?: simulações para a UERJ. Texto Para Discussão: CEDE/UFF, Niterói, p.1-21, 2013.

MURIEL, W.; GIROLETTI, D. Captação e retenção de alunos no ensino superior. Cultura E Fé, Rio de Janeiro, v. 15, n. 62, p. 59-81, mar./abr. 2010.

NERI (Org.). Você no mercado de trabalho. Rio de Janeiro: FGV, 2008. 62 p.

O'REAR, I.; SUTTON, R.; RUBIN, D. The Effect of Study Abroad on College Completion in a State University System. Glossari Project, [S.1.], v. 18. , n. 53, p. $1-18$, set. 2010.

OLBRECHT, A. Do academically deficient scholarship athletes earn higher wages subsequent to graduation? Economics of Education Review, [S.1.], v. 2, n. 28, p.611-619, 2009.

PEDROSA et al. Academic performance, students. Higher Education Management and Policy, Paris, v. 19, n. 3, p.1-16, 2007. 
ROBST, J.; KEIL, J.; RUSSO, D. The Effect of Gender Composition of Faculty on Student Retention. Economics of Education Review, Binghamton, v. 18, n. 56, p. 429-439, 1998.

SANDER, R. A systematic analysis of affirmative action in american law schools. Stanford Law Review, Stanford, v. 17, n. 68, p. 367-483, 2004.

SCOTT, M.; BAILEY, T.; KIENZL, G. Relative success? Determinants of college graduation rates in public and private colleges. U.S. Research in Higher Education, [S.1.], v. 18, n. 93, p. 249-279, 2006.

SOWELL, T. (Org.). Affirmative action around the world: an empirical study. New Haven: Yale University Press, 2004.

SULIANO, D.; SIQUEIRA, M. Retornos da educação no Brasil em âmbito regional considerando um ambiente de menor desigualdade. Economia Aplicada, São Paulo, v. 16, n. 1, p. 137-165, 2012.

WALTENBERG, Fábio; CARVALHO, Márcia de. Cotas aumentam a diversidade de estudantes sem comprometer o desempenho? Sinais Sociais, Rio de Janeiro, v. 7, p. 36-77, 2012.

Recebido em: 24/05/2013

Aceito para publicação em: 18/12/2013

\section{An analysis about the progression of quota students under the perspective of the first Brazilian affirmative action in higher education: the case of the State University of Rio de Janeiro (UERJ) Abstract}

This article examines the progression of quota and non-quota students enrolled in 2005 at the university responsible for the first affirmative action in higher education in Brazil and the results were revealing. Regarding the grade point average, it was possible to notice a worse performance among the quota students. Furthermore, we show that the difference between non-quota and quota students 
is higher in courses with high relative difficulty and that this differential has not decreased significantly over the course. When we analyzed the graduation rates and dropout, we noticed a better performance among quota students. From the analysis of the entrants of 2005 we show that the quota students have higher graduation rates in 2009, 2010 and 2011. They also have smaller dropouts during the first year and in the remainder of the course. This research concludes that the quota students enrolled at UERJ usually highly value the course they have started. Thus, they remain at a higher proportion in university, despite having lower grade point averages.

Keywords: Affirmative Action. Quotas. Progression. UERJ

\section{Análisis de la progresión de alumnos cuotistas bajo la primera acción afirmativa brasileña en la enseñanza superior: el caso de la Universidad del Estado de Río de Janeiro}

\section{Resumen}

Este artículo analiza la progresión de candidatos cuotistas y no cuotistas que ingresaron en el año 2005 a la institución responsable por la primera acción afirmativa en la enseñanza superior brasileña. Los resultados fueron sorprendentes. Sobre el tema de los coeficientes de rendimiento (CR), se observó un peor desempeño entre los cuotistas. Además, quedó claro que la diferencia entre los no cuotistas y cuotistas es mayor en cursos con alta dificultad relativa y que los diferenciales de CR no han disminuido significativamente a lo largo del curso. Al focalizar el tema de los índices de graduación y evasión, se observa un mejor desempeño entre los cuotistas. A partir del estudio del grupo definido, se observa que los cuotistas presentan mayores índices de graduación en el año 2009, 2010 y 2011. También constan menos evasiones durante el primer año y el resto del curso. Este estudio concluye que los cuotistas de la UERJ tienden a atribuir un alto valor al curso que ingresan. Por tal motivo, persisten en una mayor proporción en la universidad a pesar de menores coeficientes de rendimiento medios.

Palabras-clave: Acción Afirmativa. Cuotas. Progresión. UERJ 